\title{
Crenças na prática de ensino de inglês: um estudo de cognições de professoras orientadoras
}

\author{
Simone Reis \\ Débora Rebouças Milani Cecci ${ }^{1}$ \\ Universidade Estadual de Londrina - UEL
}

\begin{abstract}
RESUMO: Este artigo relata resultados parciais de uma pesquisa que focaliza significados do processo de escrutínio de crenças na Prática de Ensino de inglês na Universidade Estadual de Londrina. Objetivando revelar tanto o valor que cinco orientadoras dão à discussão de crenças quanto o valor que percebem ser atribuído por seus alunos-professores a tal procedimento, o estudo analisa cogniçóes do professor. Dados de entrevistas semi-estruturadas, conduzidas no início e final no ano de 2006, foram analisados com base na Grounded Theory e discutidos a partir das perspectivas da cognição e cognição situada. Essas perspectivas, respectivamente, permitem melhor compreensão de duas tendências entre as orientadoras: uma aparentemente impermeável ao contexto e caracterizada pela estabilidade de cogniçōes, e outra, sensível ao contexto, revelada por mudança nas cogniçōes.
\end{abstract}

PALAVRAS-CHAVE: escrutínio de crenças, educadores de professores, cognição, cognição situada.

ABSTRACT: This article reports on partial results of an investigation that focuses on meanings of the process of scrutiny of beliefs in the English Language Teaching Practicum at the State University of Londrina. Aiming at revealing both the value that five teaching practicum advisors give to the discussion of beliefs, and the value they perceive their student teachers to give to such procedure, the study analyses teacher cognitions. Data from semi-structured interviews carried out at the beginning and at the end of 2006 were analysed with the support of Grounded Theory, and discussed from the perspectives of cognition, and situated cognition. These perspectives, respectively, enable a better understanding of two tendencies found among the advisors: an apparently context-insulated one, characterised by the stability of cognitions, and a context-sensitive one, revealed by change in cognitions.

KEYWORDS: Beliefs scrutiny, teacher educators, cognition, situated cognition

${ }^{1}$ Bolsista PIBIC-UEL. 


\section{Introdução}

Inserido no crescente discurso em favor da formação de professores reflexivos, o exame de crenças vem sendo há bom tempo recomendado como forma de provocar nos professores a revisão e/ou mudança de suas crenças (e.g. RICHARDSON, 1996; FEIMAN-NEMSER; REMILLARD, 1996; DARLING-HAMMOND et al., 2005 - na Educação; BARCI, 2006; LUZ, 2006; GIMENEZ; MATEUS; ORTENZI; REIS, 2000; ABRAHÃO, 2001; SILVA, 2001; CARVALHO, 2000; BORSATO, 1999; BARCELOS, 1995; REIS, GIMENEZ, ORTENZI; MATEUS, 2001; GIMENEZ, 1994; FREEMAN, 1991 - na Lingüística Aplicada). A crenças atribui-se a qualidade de filtro de novas experiências, que tanto pode aceitá-las quanto rejeitá-las (e.g. FEIMAN-NEMSER; REMILLARD, 1996; RICHARDSON; PLACIER, 2001), e, como consequiência, contribuir ou não para a concretização de mudanças educacionais (RICHARDSON; PLACIER, 2001; DARLINGHAMMOND; BRANSFORD, 2005).

Na pesquisa, enquanto alguns relatos identificam o conteúdo de crenças (e.g. GIMENEZ, 1994; PUPO, 1996; GIMENEZ; MATEUS; ORTENZI; REIS, 2000; BARCI, 2006; BORSATO, 1999; CARVALHO, 2000; ASSELIN, 2000; SILVA, 2001; LUZ, 2006), outros exploram suas origens (e.g. BARCELOS, 1995; SILVA, 2005), a coerência entre as crenças e a prática (JOHNSON, 1992; BARCELOS, 1995), e o impacto da formação de professores sobre aquelas (e.g. WRAY, 1993; BENNET; CARRÉ, 1993; SILVA, 1998; REIS; GIMENEZ; ORTENZI; MATEUS, 2001; PEACOCK, 2001; HOLT-REYNOLDS, 2000; FARRELL, 2001; MANY, HOWARD; HOGE, 2002).

Paralelamente à profusão de pesquisas sobre crenças, questiona-se a eficácia de procedimentos adotados em cursos de educação formal para atingir os pretendidos fins de formação de professores reflexivos (e.g. CALDERHEAD, 1993; KORTHAGEN, 2001; ZEICHNER, 2002). Pouco se sabe, ainda, sobre como educadores e futuros professores percebem processos de explicitação e discussão de crenças educacionais durante a preparação formal destes. Por vezes, como resultados subsidiários - e não como resposta a uma pergunta para esse fim -, encontram-se comentários sobre a apreciação de alunos em relação a procedimentos voltados à promoção de reflexão nos cursos de formação (e.g. ABRAHÃO, 2001). Na pesquisa educacional, relatam-se valores ambivalentes que ex-alunos de um curso de formação de professores deram à abordagem reflexiva nele adotada (i.e. KORTHAGEN, 2001). 
Visando a contribuir para reduzir essa lacuna de conhecimento, este artigo apresenta resultados parciais de uma pesquisa sobre os significados do processo de discussão de crenças na Prática de Ensino de inglês (doravante PEI) na Universidade Estadual de Londrina ${ }^{2}$. As partes que se seguem a esta introdução dão conta da metodologia adotada e perguntas de pesquisa, do referencial teórico, dos resultados e sua interpretação e das consideraçôes finais.

\section{Metodologia}

Sob princípios da pesquisa qualitativa (MILES; HUBERMAN, 1994; COHEN; MANION; MORRISON, 2002), a investigação original da qual deriva este relato envolveu cinco orientadoras e 10 alunos-professores. Por adequação ao espaço de publicação, aqui focalizamos somente dados relativos àquelas. Os dados provêm de entrevistas semi-estruturadas gravadas em áudio e realizadas no início e final do ano de 2006 na Universidade Estadual de Londrina. Tínhamos em mente responder às seguintes perguntas, sendo que neste relato restringimo-nos às duas primeiras, destacadas em itálico:

1. Que valor(es) orientadoras atribuem à discussão de crenças na PEI?

2. Que valor(es) orientadoras percebem ser atribuidos pelos alunos-professores à discussão de crenças na PEI?

3. Que valor(es) alunos-professores atribuem à discussão de crenças na PEI?

4. Que valor(es) alunos-professores percebem ser atribuídos pelas orientadoras à discussão de crenças na PEI?

Das cinco professoras orientadoras, duas atuavam na PEI havia menos de cinco anos; duas outras, mais de 10 anos; e uma, mais de 20 anos. Todas cursaram Letras na mesma instituição onde os dados foram coletados, quatro delas cursaram especialização em Língua Inglesa, três delas, mestrado, e duas, doutorado.

A abordagem analítica combina a dedução, a partir das respostas diretamente dirigidas a perguntas do roteiro de entrevista, bem como a indução,

${ }^{2}$ Este relato deriva do projeto de pesquisa intitulado Significados do processo de explicitação e discussãa de crenças educacionais: Um Estudo sobre a interação de professores e alunos-professores, registrado na Pró-Reitoria de Pesquisa e Pós-Graduação da Universidade Estadual de Londrina. 
a partir de tentativas de agrupar os dados em torno de temas recorrentes. Metodologicamente, esse esforço tem respaldo nas técnicas da Grounded Theory (STRAUSS; CORBIN, 1990).

As duas perguntas de pesquisa - objeto deste relato - são retomadas a partir dos subtítulos da seção de análise. Cada asserção é acompanhada de um excerto ilustrativo de transcrição das entrevistas. Nas referências das transcrições, adotamos estas convençóes:

1. colchetes para sinalizar a origem dos dados ou informação fornecida pelas pesquisadoras;

2. abreviatura ENT, que indica o instrumento entrevista, seguida de numeral que se refere à seqüência de sua realização; hífen seguido do código da respectiva professora orientadora (PO).

Exemplo: Ah, eu vejo meu papel como de orientá-los, de aprender com eles, de éh construir juntos. [ENT01-PO1].

Em seguida, passamos à interpretação das duas respostas às perguntas de pesquisa, à luz dos pressupostos da cognição e da cognição situada, utilizando novos excertos dos dados, com finalidade argumentativa. Fazemos isso para emoldurar as percepções das orientadoras no contexto de aprendizagem no trabalho.

Diferentemente de outras investigações sobre crenças que também adotaram um único instrumento de coleta de dados (e.g. MANNA; MISHEFF, 1987; WRAY, 1993; PUPO, 1996; ASSELIN, 2000; HOLTREYNOLDS, 2000; TERCANLIOGLU, 2001; PEACOCK, 2001; FUNG; CHOW, 2002), para assegurar a qualidade desta pesquisa, a análise foi objeto de triangulação por pesquisadores (COHEN; MANION; MORRISON, 2002) e pelas participantes.

Retornar às orientadoras a análise feita para triangulação é, mais do que um cuidado metodológico, uma preocupação ética. Ao compartilharmos com cada uma a análise feita sob as visões teóricas explicitadas, pedimos também que indicassem outra(s) teoria(s) que julgassem pertinente(s) para discutir as respostas às duas perguntas de pesquisa. Todas as orientadoras concordaram com a análise realizada. Uma delas sugeriu alternativamente discutir seus dados a partir da cognição distribuida, para finalidade de estudo de caso. No presente estudo, contudo, esta perspectiva é considerada sinônima de cognição situada (Cf. PACKER; WINNE, 1995). 


\section{Referencial teórico}

Tendo em vista que o objeto de percepção que se pretendeu captar é a discussão de crenças, aqui explicitamos em que termos entendemos o que estas representam, recorrendo a intravisões da Filosofia da Educação e da Psicologia: Comparando crença com pensamento, Dewey defende que a crença repousa sobre um conhecimento pressuposto, que vai além do que está diretamente presente; ela "é marcada pela aceitação ou rejeição de algo como razoavelmente provável ou improvável” (1910, p. 4). Para o filósofo-educador, algumas crenças são passíveis de aceitação independentemente de suas bases terem sido examinadas ou não. Enquanto tipos de pensamento, elas provêm de fontes obscuras que inconscientemente se tornam parte da "mobília mental" humana (DEWEY, 1910, p. 4). Para Richardson (1996), pesquisadora de orientação construtivista, crenças é um conceito psicológico que difere de conhecimento, posto que este implica garantia epistemológica (p. 104). Para Bruner (2004), psicólogo, o pensamento não é apenas uma realização individual, mas é também social.

Além desse entendimento de crença, apoiamo-nos nos conceitos da cognição e a cognição situada, para entender como as professoras orientadoras se posicionam em seu trabalho quanto ao valor que atribuem e percebem ser atribuídos à discussão de crenças. As orientadoras são, portanto, vistas como pessoas em processo de aprendizagem no seu trabalho.

A perspectiva da cognição apregoa a existência e papel central de um amálgama cognitivo, independente do contexto e de intençôes, sobre o indivíduo (PUTNAM; BORKO, 1997). Estudos nessa perspectiva focalizam processos que se desdobram ao longo do tempo, nos quais informaçōes, crenças e outros conteúdos mentais são manipulados, reestruturados e construídos (PACKER \& WINNE, 1995). Criticadas por ignorarem o contexto em que se insere o indivíduo (PUTNAM; BORKO, 1997), tais investigaçóes, contudo, permitem conhecer mudança de cognições como processo individual (e.g. STOIBER, 1991; GUILLAUME; RUDNEY, 1993; KWO, 1996; WRAY, 1993; FARRELL, 2001), bem como a impermeabilidade de indivíduos a novos conhecimentos que encontram no contexto (e.g. MCNALLY; COPE; INGLIS, 1997; TILLEMA, 1998; SPALDING, 2002; HOLT-REYNOLDS, 2000; REIS, 2005).

$\mathrm{Na}$ cognição situada, o contexto, que é físico e social, prevalece sobre o indivíduo. Sua força é tanto de restringir quanto de fornecer fontes para atividades serem desenvolvidas (PACKER; WINNE, 1995). Ele é uma parte 
integral da atividade de aprendizagem, e a atividade, por sua vez, é uma parte integral da aprendizagem que nele se realiza (PUTNAM; BORKO, 1997). Compensando a crítica que estudos nessa linha recebem por atribuírem ao contexto um papel determinante na aprendizagem (PACKER; WINNE, 1995), argumenta-se que o conhecimento é construído na interação com o ambiente, e que tanto este quanto o indivíduo mudam como resultado de um processo de aprendizagem (RICHARDSON, 1997; e.g. ANDREWS; MOSS; STANSELL, 1985; MOSENTHAL; SCHWARTZ; MACISAAC, 1992; ANTONEK; MCCORMICK; DONATO, 1997; RAYMOND, 2002; KWO; ADAMSON; TAVARES; TANG; WONG, 2003; MORINEDERSHIMER, 2003; FANG; ASHLEY, 2004; REIS, 2005).

\section{Resultados}

\section{Valor(es) que as educadoras atribuem à discussão de crenças na PEI}

Ao examinar as declarações das cinco orientadoras sobre o valor que atribuem à explicitação e discussão de crenças educacionais na formação de professores, ficou evidenciada a tendência de algumas a descrever como fazem a discussão de crenças, em vez de responder de modo direto a essa pergunta. Também ficou claro que ao longo de um ano o valor que atribuem a tal prática se modifica para duas delas. A análise a seguir primeiramente agrupa os resultados obtidos pela interpretação das entrevistas realizadas no início de 2006, passando, na seqüência, a se embasar nos dados da segunda entrevista.

Para as PO1, PO3 e PO4, a discussão das crenças com seus alunos é muito importante:

Eu acho que pra eles [a discussão das crenças] é sempre muito relevante. Aí, a gente vê nas salas deles, seja nas salas informais ou nas salas onde a gente faz pesquisa éh... como isso é importante pra eles perceberem seu lugar, né... éh... o lugar disso no desenvolvimento profissional, né, e nas dificuldades que eles têm, nas dificuldades que eles encontram... [ENT01-PO1].

Eu acho que eu dou valor nesse ponto de que elas [as crenças] são o ponto de partida pras minhas aulas [ENT01-PO3].

Eu dou uma importância muito grande, né, porque isso me faz eh... quando eu comecei a trabalhar, né, como formadora de professores e, 
e fazer pesquisa também nessa área, eu me identifiquei muito com o trabalho de crenças porque eu me vi em várias situações eh na minha formação, né, de quando eu estava fazendo o curso, de que isso não era levado em conta, né? E eu falava assim, bom, tá, eu fazia aquilo só pra cumprir o que os meus professores pediam, mas na verdade não era aquilo que eu pensava, não era aquilo que eu fiz depois que eu me formei, então, porque, talvez se essas crenças tivessem sido, né, trazidas à tona, sei lá é... Eu me identifiquei muito com esse trabalho porque eu falei "ah, é isso mesmo, nós não somos zero e entramos no curso de formação e vamos sair dali prontos e acabados”. Então, eu dou muita importância e por isso procuro valorizar muito as crenças dos meus alunos...[ENT01-PO4].

PO2 e PO5, embora informem realizar discussão de crenças, priorizam aspectos da prática na formação. PO2 relata sua preferência pela busca de soluções com os alunos para problemas da prática à discussão de crenças, enquanto que $\mathrm{PO} 5$ expõe maior preocupação com o tratamento que as crenças recebem mais do que com sua própria discussão, conforme estes excertos:

Então, nessa parte é que entra meu papel de tentar não homogeneizar o conteúdo do assunto, enfim, né, aí eu acho que entraria o papel pra tentar discutir pra uma solução, não só ficar naquela do debate teórico, enfim, mas tentar colocar aquilo: "Tá, nós temos esse quadro aí, como é que a gente vai tentar solucionar isso aqui da melhor forma ou então da forma que a gente vai conseguir?" [ENT01-PO2].

Pra mim, o que não bastava só... eu acho importante lidar com isso, mas, assim, o que a gente faz com isso eu acho mais importante ainda, né, o que você faz com esse conjunto de crenças, de conhecimento que o aluno tem, eh, se ele está se sentindo satisfeito, por que ele acha que aquilo que ele está tendo ou trabalhando não está sendo suficiente naquilo que ele acredita [ENT01-PO5].

A partir das entrevistas realizadas ao final de 2006, identificamos mudança no valor que $\mathrm{PO} 1$ e $\mathrm{PO} 4$ atribuíam à discussão de crenças. Ambas passaram a dar menor valor a tal prática: $\mathrm{PO} 1$, pelo interesse na aprendizagem dos alunos como elemento para entender a prática dos alunos-professores no contexto escola; $\mathrm{PO} 4$, por observar que seus alunos se cansam da discussão de crenças, senão vejamos: 
Neste momento da minha vida profissional eu diria que a discussão de crenças é uma parte menos importante no meu trabalho do que ela já foi, né, do que ela comumente foi. Eu acho que hoje a discussão das crenças, das maneiras como os alunos é (...) entendem, né, que seja ensinar e aprender, elas são importantes, sim. Elas, acho que revelam muitas das maneiras como se pretende conduzir o trabalho deles, mas não têm sido muito objeto das minhas discussões e eu não tenho tentando entender muito as práticas dos alunos a partir disso, né, eu acho que hoje eu busco mais entender a prática dos alunos, no contexto em que a gente atua, junto com os professores e tendo como é (...) parâmetro, não é bem parâmetro, mas como um elemento de (...) de análise a aprendizagem das crianças na escola [ENT02-PO1].

Eu costumava dar mais valor a essa discussão, hoje eu tenho dado um pouco menos de valor, né, eu acho que os alunos, eles andam um pouco meio cansados disso, de discutir, eles falam "ah, professora, a gente discute, discute, discute, não chega a lugar nenhum. Tudo pode, tudo não pode". Então, eu tenho ido um pouquinho menos longe, vamos dizer assim: eu extrapolava um pouco mais, ou seja, dava então um pouco mais de valor. Hoje eu dou menos valor a essa discussão [ENT02PO4].

$\mathrm{O}$ valor que $\mathrm{PO} 2, \mathrm{PO} 3$ e $\mathrm{PO} 5$ atribuíam à discussão de crenças no início de 2006 parece não ter sido alterado em relação ao que expuseram ao final daquele ano. Preocupações com a prática continuam presentes na fala de PO2, que não estende as discussóes das crenças, tendo em vista o fator tempo:

Essa ênfase sobre as crenças é mais discutida no começo, no início do terceiro ano e é claro que a gente sempre leva em consideração no quarto ano também, né, porque a gente sempre faz as discussões éh (...) de início, antes deles irem no quarto ano também, antes deles irem a campo, então a gente faz a discussão e os alunos colocam todos os medos, né, porque muitos deles não éh (...) nunca atuaram, nunca foram professores, tal, então eles colocam os medos, as inseguranças, aquela coisa toda e (...) as crenças também sobre o ensino da escola pública, sobre todo o contexto que eles vão atuar, né, então eu tento trabalhar um pouco isso também, mas é (...) não é aquela discussão tão (...) longa, né, a longo prazo porque a gente não pode perder tempo 
assim e como eles já fizeram essa discussão no terceiro ano a gente tem que trabalhar nas partes mais práticas no quarto ano porque eles já tão indo pra campo de estágio, eles vão dar aula, né, então é uma coisa mais prática [ENT02-PO2].

Para a PO3, a discussão de crenças continua sendo importante:

Eu acho super valoroso, tem que discutir as crenças mesmo embora a (...) se é pra haver alguma alteração na crença desses meus estagiários. Isto ainda não foi possível acontecer em um ano de trabalho porque na verdade não foi um ano de prática de sala de aula. Então, as crenças em muito não foram alteradas. Se elas deveriam ter sido, passou-se mais um ano, estou formando mais um grupo de alunos que eu não vi alteração de crenças como eu gostaria que tivesse acontecido [ENT02-PO3].

PO5 discute crenças sem que esse seja o foco, por considerar que isto é uma parte e não um fim da formação de professores:

Daí, quando eu solicitava isso, o aluno era capaz, a aluna era capaz de localizar exatamente o quê, né, e aí a gente conversava um pouco, mas sem tá entretanto enfocando que o que nós estávamos fazendo era discutindo crenças. Eu acho que eh... isso fica num plano mais subliminar, né, e eu acho que se aluno se engaja nesse tipo de resposta e ele até se envolve, porque essas geralmente eram eh... esses eram inícios de discussões que talvez iriam até parecer digressões na aula, do foco da aula, por quê? Porque todo mundo queria dizer alguma coisa, todo mundo tinha alguma coisa pra acrescentar. Então, eu acho que eram momentos bastante provocativos e que talvez se você perguntasse mais diretamente a elas [alunas-professoras], elas não iriam perceber dessa maneira, assim como sendo uma discussão de crenças, né, e mais como discussão de questões, de tópicos, né, ah (...) o que é crença eu acho que ficava mais subliminar [ENT02-PO5].

O que não tá muito explícito [...] é que a gente tá discutindo crenças, né. Eh... que a gente está, isso acho que a gente está a todo minuto enquanto está interagindo, mas não é, não é com essa tônica, não é pra isso que eu quero que elas [as alunas-professoras] estejam olhando (...) eu acho que a discussão de crenças, ela passa a ser meio ao invés de ser fim da formação de professores [ENT02-PO5]. 
Em síntese, as professoras orientadoras, em extensões individuais, valorizam a explicitação e discussão de crenças educacionais na formação de professores, sendo que duas delas passam a atribuir menor valor a tal procedimento; uma mantém-se preocupada também com questôes ligadas à prática de ensino, outra discute crenças sem fazê-lo explícito, pois para ela a discussão de crenças é um meio e não o fim da formação, e, finalmente, uma orientadora conserva alto valor à discussão de crenças.

\section{Valor(es) que as orientadoras percebem ser atribuídos pelos alunos-professores}

As percepções das orientadoras divergem quanto ao valor que os alunosprofessores dão à discussão de crenças. Aqui, descartamos a comparação sistemática entre as respostas à primeira entrevista com as da segunda porque duas orientadoras (PO1 e PO5) respondem a essa pergunta apenas na segunda entrevista.

Segundo PO2 e PO4, os alunos-professores não gostam ou ainda não valorizam a discussão de crenças:

Bom, como eu tinha falado antes, é não completamente menosprezar as crenças justamente porque isso é baseado nas observações ou experiências, não digo nem observações, mas nas experiências dos próprios alunos e a discussão quando os alunos, e eu vou te dar a real, tá, às vezes eles não gostam de discutir isso em sala de aula porque eles acham que é perder tempo falando sobre este tipo de coisa que já é uma, eles já tomam como fato dado, entendeu? [ENT01-PO2].

Os alunos, eu vejo que os alunos ainda não valorizam muito esse trabalho, eles ainda ficam com um pé atrás, assim: "Nossa, pra que tá falando disso, por que tá falando isso?”, né... eh... eu já tive situações onde o aluno falava assim: "mas, nossa, professora, mas quando que a gente vai começar mesmo, né, a disciplina do terceiro ano, o assunto do terceiro ano, a prática de ensino?", né. Eu falei: “ah, nós já começamos, né..." Então, eu percebi que aquilo pra ele ainda não era, né, era só contar história, talvez, quando a gente faz história, né, a linha de vida e pede pra eles que façam a deles, então, que é uma primeira atividade que a gente faz no terceiro ano, então... eh... eu vejo assim que eles ainda ficam um pouco com o pé atrás em relação a isso, né, eles ficam questionando 
se isso não é muito subjetivo, né, quanto, o quanto a gente vai conseguir com essa subjetividade, se não era melhor uma formação mais éh... prescritiva mesmo, éh ensinando métodos pra eles e técnicas. Eles questionam isso: "por que que a gente não tem isso, em vez de ficar falando de crenças", por que que a gente não ensina eles a darem aula, muitos alunos perguntam [ENT01-PO4].

Para PO3, seus alunos-professores apreciam a discussão de crenças, uma percepção que se mantém da primeira para a segunda entrevista:

Eu acredito que eles dêem valor, não sei se eles apreendem essas crenças, né... $\mathrm{O}$ ano passado, com esse questionário que nós aplicamos parece que sim, não é, mas, até então, antes da aplicação desses questionários, eu não tinha mesmo uma coisa mais concreta pra dizer que eles dão esse valor... [ENT01-PO3].

Eu acho que eles gostam de discutir, parece que quando a gente é (...) começa discutir crenças em sala de aula é (...) há uma grande participação dos alunos, eles ficam motivados, eles querem é (...) mostrar o que eles pensam e realmente eles participam da aula, alguns são mais tímidos, mas acabam expondo suas idéias é (...) acho que até o momento de catarse quando todo mundo põe pra fora o que, que eles pensam, é até muito gostoso [ENT02-PO3].

Na segunda entrevista, PO2 tem uma percepção diferente:

Eu acho interessante, ele (...) ele, os alunos é (...) gostam, né, porque justamente porque a gente (...) nós não fazemos trabalho de diário, de anotações de campo nem nada. Então muitas coisas que a gente discute no começo do ano, acaba se perdendo no final, né, mas é legal porque eles vão refletindo durante o trabalho, sabe, no quarto ano você vê isso, sabe, os alunos discutem o começo e depois no meio enquanto eles estão fazendo as atividades lá como regentes, né, professores regentes, aí eles vão falando 'olha', eles vão lembrando das coisas que eles acreditavam e que depois continuam ou então coisas que, enfim, mudaram [ENT02-PO2].

Já PO4 mantém inalterada sua percepção de que os alunos-professores não gostam e dão pouco valor à discussão de crenças: 
Olha, inicialmente o valor é muito pequeno, eles não gostam de fazer isso, tá. É (...) eles não conseguem (...) eu acho que eles não conseguem ver, eu acho que ainda a gente tá dentro de um modelo é (...) bastante prescritivo, ou seja, bastante tradicional de que os alunos estão aqui para aprender teorias e ir lá e aplicar, por exemplo, acho que o aluno em si não consegue ver ainda essa ligação do que ele traz já que é importante também pra somar ou pra dividir, ou pra multiplicar, sei lá, com aquilo que ele vê aqui na universidade. Acho que nós éh, supervisores, acreditamos mais nisso, muito mais, né, e sabemos da importância disso. Agora não sei se a gente consegue mostrar pros alunos, não sei se eu consigo mostrar pra eles que é importante, eu acho que não, porque a resposta deles não é tão positiva, vamos dizer, pra mim, eu tenho (...), sabe, me parado muito pra pensar sobre isso: "será que eu não consigo mostrar" (...) eu acho importante, mas eu não sei se eu não consigo mostrar pra eles ou se não sou eu que tem que mostrar, não sei, eu acho que eles dão pouco valor (...) [ENT02-PO4].

Eu acho que eles dão pouco valor a essa discussão de crenças, eu acho que eles acham que a gente enrola a aula com isso, vou ser bem sincera [ENT02-PO4].

Para PO1 e PO5, o foco dos alunos-professores é alternativo à discussão das crenças:

acho que pra eles também as crenças são importantes, a gente discute, elas aparecem muitas vezes, né, mas eles também acho que dão mais importância pra, pros processos de aprendizagem, como é que a gente aprende, né, mais de (...) "porque que eu aprendo assim”, né, ou "porque que eu quero fazer assim”, tá, então eu acho que igualmente pra eles, aí é uma percepção minha, né, acho que seria interessante saber deles mas eu imagino que, da maneira como a gente vem conduzindo os trabalhos, isso também se tornou éh (...) foi colocado num segundo plano. Ele não é irrelevante, sem importância, mas acho que tá num segundo plano, ele é mais completar do que, sei lá, ponto de partida como por muito tempo foi, né [ENT02-PO1].

Acho que alguns dos alunos valorizam bastante, não essa discussão, mas a oportunidade de colocar os seus pontos de vista em sala de aula ou 
mesmo fora da sala de aula, mas sempre tratando de conteúdos pedagógicos, de conteúdos educacionais, acho que valorizam, sim [ENT02-PO5].

Conforme expusemos, os valores que as orientadoras percebem ser atribuídos por seus alunos-professores à discussão de crenças são divergentes. Algumas orientadoras relatam sobre aqueles que apreciam e aqueles que não gostam de discutir crenças. Outras têm foco alternativo a essa discussão: a aprendizagem dos alunos e outras questôes pedagógicas. A não-valorização ou a menor valorização da discussão de crenças por parte dos alunos-professores parece atrelada à idéia de desperdício de tempo diante de necessidades práticas. A valorização, por outro lado, parece ligada à possibilidade de fazer conexões entre a experiência prática de sala de aula com conteúdos de discussóes que a antecederam. Paralelamente, a discussão de crenças fica em segundo plano quando o foco dos alunos-professores recai sobre os processos de aprendizagem dos alunos e outras questôes pedagógicas.

\section{Interpretação dos resultados}

A análise dos dados das cinco orientadoras possibilitou-nos identificar tendências que podem ser melhor compreendidas pelas óticas da cognição e da cognição situada. Dentre todas as professoras orientadoras, PO3 é a única que afirma conceder grande valor à discussão de crenças, tanto no início quanto no final do mesmo ano, bem como acreditar que seus alunos professores apreciam isso. Conforme seu depoimento, até um ano antes ela não dispunha de algo concreto que the permitisse saber se os alunos valorizavam ou não essa discussão. O que acontece no trabalho de discussão de crenças, como essa orientadora lida com as crenças de seus alunos são evidentemente outros objetos de análise, que, no entanto, oferecem pistas para entender a natureza de sua convicção da importância da discussão de crenças, inclusive como ponto de partida da educação de professores.

PO3 externou que a discussão de crenças, que comparou a uma catarse, gera conflitos, pois nela se dá o choque de suas crenças com as dos alunos. No seu depoimento, $\mathrm{PO} 3$ revela muitas vezes desempenhar o papel de modelo para seus alunos, o qual impóe àqueles que não trazem o perfil de professor que ela julga necessário. No caso de PO3, a perspectiva da cognição tem um potencial explanatório para sua convicção em relação à discussão de crenças: a orientadora traz para o contexto de seu trabalho uma posição a respeito da 
importância da discussão de crenças, que não se altera ao longo de um ano, diante dos mencionados conflitos nas discussóes, da falta de elementos que a informem sobre o que pensam os alunos-professores a respeito de tal discussão. Portanto, nesse caso, o valor da discussão das crenças parece determinado pelas cognições da orientadora formadas previamente à sua entrada no ano em tela.

Encontramos nos dados, indicativos de como PO3 se coloca diante do exame de crenças em seu trabalho. Os dois excertos a seguir revelam o que ela vivencia nas discussões com seus alunos, sua percepção de grande discrepância entre suas crenças e as de seus alunos-professores, e a diferença como uma fonte de atrito.

Às vezes me vejo como uma pessoa que dita modelos e saio da aula frustrada porque eu não gostaria que fosse assim. Eh... Uma pessoa que está ditando modelos para os alunos... Eh... Outras vezes tenho grandes discussōes com os alunos por conta de tentar tirar deles as justificativas, por que eles acham que dar aula deve ser desse jeito ou daquele jeito. Temos grandes discussóes... [ENT01, PO3].

Às vezes gera conflitos. A minha crença e a crença do meu aluno, né? Tem conflitos, tem, tem brigas, tem mal estar na sala de aula, ou nas orientações individuais, né? Atritos muito desagradáveis, às vezes, porque... Mas esses atritos, acho que acontecem com esses alunos que não querem ser professores e se vêem obrigados a preparar uma aula, a discutir, né? Ou então... eh... o conflito está porque esse aluno alega ter uma história de vida, né, que ele requer refletir no estágio dele, que não tem nada a ver com as minhas crenças e com as leituras que nós fazemos em sala de aula. Então, acho que as nossas crenças, minhas e dos meus alunos às vezes, eu até diria que $50 \%$ das vezes, são conflitantes [ENT01, PO3].

Entre as demais orientadoras - PO1, PO2, PO4 e PO5 -, a cognição situada favorece a compreensão de suas posições sobre a discussão de crenças. Suas mudanças de cognições do início para o final do ano são verbalizadas levando-se em conta fatores relacionados ao contexto. Sensíveis a esse contexto marcado por crenças e expectativas por vezes divergentes de alunos-mestres, por uma estruturação de tempo curricular para promover a formação de professores, as orientadoras compartilham do pensamento de que seu papel na discussão de crenças não é impor suas próprias aos alunos-professores. Essa 
discussão é vista como espaço de expressão de vozes, de formação e revisão de posições. Ela serve para fornecer, pelas crenças dos alunos-professores, indicaçóes do que pode acontecer na sala de aula, e é a realização da prática foco de maior interesse dos alunos-professores - preocupação da maioria dessas formadoras. Suas cognições, portanto, levando em conta as dos alunosprofessores com quem interagem, são (re)construídas no contexto da educação de professores. Tanto a menor ênfase à discussão de crenças ao longo do ano percebida pelas orientadoras quanto sua percepção do propósito dessa discussão sugerem estarem considerando o outro, o aluno-professor.

$\mathrm{Na}$ seqüência, apresentamos dois excertos das entrevistas de cada orientadora para ilustrar sua percepção sobre a discussão de crenças, o seu posicionamento nessa dinâmica e diante das vozes de seus alunos-professores.

PO1:

[...] Eu faço um esforço e aí é um esforço, porque eu não acho que eu consiga, mas eu faço um esforço consciente de tentar condicionar minhas aulas num espaço mais democrático mais interativo de voz para esses alunos, pra que eles, eh, assumam cada vez mais responsabilidade pelo seu processo de aprendizagem... [ENT01-PO1].

Eu acho que é importante pra eles, pra mim e pra revisão dessas crenças, né, eu não tenho a pretensão aí, e o motivo não é querer moldar, mudar, modificar essas crenças, mas poder trabalhar a partir delas, pra eles, eh, ter[em] um envolvimento, deles com a atividade [ENT01-PO1].

PO2:

Mas agora tentar mudar isso [as crenças] é uma coisa que é difícil pra $\mathrm{mim}$. Eu acredito que eu não tento fazer isso com meus alunos também porque é uma coisa que existe é uma realidade né e... [ENT01-PO2].

[...] então eu não tento meio que impor isso pros alunos... [ENT01$\mathrm{PO} 2]$.

PO4:

Eu nem espero que ele [o aluno-professor] mude essa crença, porque eu acho que não é esse o nosso papel, né, porque, se não, a gente estaria bem dentro de um modelo prescritivo querendo que ele mude a crença dele, eu acho. Eu não me vejo assim como formadora. Pode ser até que eu 
faça isso na prática, né, não sei, mas não é essa, não é esse o propósito [ENT01-PO4].

[...] Eu me questiono bastante também se eu não estou querendo que eles assumam as minhas crenças, né. Então, eu também fico me policiando pra ver até que ponto, tá, eu levanto as crenças deles, faço questão que eles coloquem isso. Acho que isso é importante pra, a partir dali, né, as nossas discussões, mas também me vejo algumas vezes, né, e penso algumas vezes também: "será que eu não tô querendo que ele tenha a minha crença?”, né. Então, também fico me policiando. Às vezes, me vejo fazendo isso tentando meio que não impor, mas fazendo questionar, questionar [ENT01-PO4].

PO5:

[...] Acho que tem que ter essa discussão da crença, é muito importante quando ela permite que o aluno seja superfranco naquilo que ele está fazendo ou que ele espera, se ele está gostando ou não. Se a discussão acontece, eu acho que, se ela não levar em conta essas apreciações do aluno, acho que ela não tem nenhuma validade [ENT01-PO5].

[...] Na preparação de materiais, na discussão, né, do que está por trás dessa preparação [de materiais], não em termos do que seria assim o ideal pra se chegar, porque esse ideal pra se chegar é muito questionável, né, quem é que estabelece o ideal pra se chegar, mas em termos do eh... o que, que motiva a pessoa a preparar uma atividade de determinada forma [ENT02-PO5].

Nesta subseção, interpretamos as respostas às duas perguntas de pesquisa, fornecendo excertos dos dados das orientadoras que abrem a possibilidade de entender por que PO3 mantém sua percepção do grande valor da discussão de crenças, apesar dos conflitos que nela experimenta em virtude da diferença entre suas crenças e a de seus alunos-professores. Tanto seu relatado desconhecimento sobre se estes valorizam (ou não) a discussão de crenças quanto sua convicção do valor dessa prática nos sugerem ser a perspectiva de cognição, adequada para entender seu posicionamento. Por outro lado, PO1, PO2, PO4 e PO5 têm em comum relatos de posturas e expectativas que consideram as necessidades dos alunos-professores. A não-imposição de suas crenças sobre seus alunos, com as ilustrações, em subseção precedente, de que 
ou reduziram o espaço que a discussão de crenças ocupava inicialmente, ou que a realizaram sem fazer dela o foco da educação de professores, ou que passaram a enfocar a busca de soluçóes conjuntas e a aprendizagem dos alunos na escola, permitiram-nos entender sua posição a partir da cognição situada. Se tomadas como em processo de aprendizagem no contexto de seu trabalho, essas orientadoras parecem estar reconstruindo seus pensamentos na interação com seus alunos-professores.

\section{Considerações finais}

Neste artigo, relatamos resultados parciais de uma pesquisa qualitativa que retrata as percepções de professoras orientadoras na PEI a respeito da discussão de crenças na educação de alunos-professores de inglês. Mais especificamente, lidamos com as percepçóes do valor que dáo a essa prática e o valor que percebem ser atribuído a isso por seus alunos-professores.

Revelamos que a discussão de crenças é valorizada por todas as orientadoras; que o valor e, por conseguinte, o espaço que essa prática ocupa na educação de seus alunos se reduz do início para o fim do ano para quatro de cinco orientadoras. Mostramos também que, para uma orientadora, o valor desse procedimento não sofre alterações ao longo do ano em questão. Discutimos, pelas óticas da cognição e da cognição situada, as diferenças nas relatadas posturas das orientadoras no contexto de seu trabalho. Nosso propósito foi mostrar, respectivamente, que as percepçóes, o pensamento verbalizado de uma professora parecem ser determinados por cognições que independem do contexto, e que, para quatro professoras, as mudanças de suas cognições parecem levar em conta as necessidades de seus alunos-professores. A maneira como todas orientadoras relataram se posicionar diante da discussão de crenças com seus alunos foi elemento de suporte para concluirmos nossa análise.

Estamos cientes que entre o dizer e o fazer existem contradições. As próprias falas das orientadoras revelam essa consciência. Por isso, enquanto esta pesquisa se restringiu aos resultados relatados, outras pesquisas com as mesmas indagaçôes podem ser conduzidas com outros registros de dados e, quem sabe, modificar as interpretações de nosso estudo. Além disso, restam ainda duas outras perguntas que originalmente direcionaram o interesse desta investigação, que podem oferecer subsídios para melhor entender os significados do processo de explicitação e discussão de crenças educacionais: que valor(es) alunosprofessores atribuem à discussão de crenças na PEI e que valor(es) alunosprofessores percebem ser atribuídos pelas orientadoras à discussão de crenças na PEI. 
Há bom tempo já se criticou a tendência de utilizar pesquisa tãosomente para dar suporte e informar a prática, em vista da parcialidade, limitações e ideologias que se impõem à educação de professores, em vez de ver pesquisa e prática em termos de questionamento e exploração recíprocos (e.g. CALDERHEAD, 1993). Se a presente disseminação de pesquisa mostra um pouco das complexidades e desafios da educação de professores, é de se esperar que, mais e mais, os participantes desse contexto desenvolvam conhecimento crítico de e sobre seu trabalho e possam, se quiserem, (re)construí-lo.

A palavra final aqui é de agradecimento: às professoras orientadoras que prontamente aceitaram participar desta pesquisa, criando espaço em suas ocupadas agendas para a realização da coleta de dados e julgamento da análise, e, somente assim, possibilitando este estudo.

\section{Referências}

ABRAHÃO, M. H. V. A formação acadêmica e a iniciação profissional do professor de línguas: um estudo da relação teoria e prática. Trabalhos em Lingüistica Aplicada, Campinas, v. 37, p. 61-81, 2001.

ANDREWS, N.C.; MOSS, R.K.; STANSELL, J.C. Reading (aloud, that is) to undergraduate reading methods classes. Journal of Reading, Newark, v. 28, n.4, p. 315-320, 1985.

ANTONEK, J. L.; MCCORMICK, D. E.; DONATO, R. The student teacher portfolio as autobiography: developing a professional identity. The Modern Language Journal, Oxford, v. 81, n. 1, p. 15-27, 1997.

ASSELIN, M. Confronting assumptions: preservice teachers' beliefs about reading and literature. Reading Psychology, Philadelphia, v. 21, n. 1, p. 31-55, 2000 .

BARCELOS, A. M. F. A Cultura de aprender língua estrangeira (inglês) de alunos formandos de Letras. 1995. 141f. Dissertação (Mestrado em Lingüística Aplicada) - Instituto de Estudos da Linguagem, Universidade de Campinas, Campinas, 1995.

BARCI, M. S. T. Investigating student teachers of a Letras Program: their beliefs and expectations about being English teachers. 2006. 96f. Dissertação (Mestrado em Letras - Inglês e Literatura correspondente). Universidade Federal de Santa Catarina, Florianópolis.

BENNET, N.; CARRÉ, C. (Ed.). Learning to teach. London: Routledge, 1993. $242 \mathrm{p}$. 
BORSATO, E. Crenças educacionais de licenciados: um estudo exploratório. 1999. 193f. Dissertação (Mestrado em Educação). Universidade Estadual de Londrina, Londrina.

BRUNER, J. Introduction to "Thinking and Speech". In: RIEBER, R. W.; ROBINSON, D. K. (Ed.). The essential Vygotsky. New York: Kluwer Academicl Plenum Publishers, 2004. p. 9-25.

CALDERHEAD, J. The contribution of research on teachers' thinking to the professional development of teachers. In: DAY, C.; CALDERHEAD, J.; DENICOLO, P. (Ed.). Research on teacher thinking: understanding professional development. London; Washington, D.C.: The Falmer Press. 1993. p. 11-18. CARVALHO, V. C. P. S. A aprendizagem de lingua estrangeira sob a ótica de alunos de Letras: crenças e mitos. 2000. 142f. Dissertação (Mestrado em Estudos Lingüísticos). Universidade Federal de Minas Gerais, Belo Horizonte.

COHEN, L.; MANION, L.; MORRISON, K. Research Methods in Education. London: Routledge, 2000. 446p.

DARLING-HAMMOND, L.; BRANSFORD, J. (Org.). Preparing teachers for a changing world: what teachers should learn and be able to do. San Francisco: Jossey-Bass, 2005. 593p.

DARLING-HAMMOND, L. et al. (2005). The Design of Teacher Education Programs. In: DARLING-HAMMOND, L.; BRANSFORD, J. (Org.). Preparing teachers for a changing world: what teachers should learn and be able to do. San Francisco: Jossey-Bass, 2005. p. 390-441.

DEWEY, J. How we think. Boston: D. C. Heath, 1910. 224p.

FANG, Z.; ASHLEY, C. Preservice teachers' interpretations of a field-based reading block. Journal of Teacher Education, Thousand Oaks, v. 55, n.1, p. 3954, 2004.

FARRELL, T. S. C. Concept maps to trace conceptual change in preservice English teachers. RELC Journal, London, v. 32, n. 2, p. 27-44, 2001.

FEIMAN-NEMSER, S.; REMILLARD, J. Perspectives on learning to teach. In: MURRAY, F. B. (Ed.). The teacher educator's handbook. San Francisco: Jossey-Bass Publishers, 1996. p. 63-91.

FREEMAN, D. To make the tacit explicit: teacher education, emerging discourse, and conceptions of teaching. Teaching and Teacher Education, New York, v. 7, n. 5/6, p. 439-454, 1991.

FUNG, L.; CHOW, L. O. Y. Congruence of student teachers' pedagogical images and actual classroom practices. Educational Research, v. 44, n. 3, p. 313-321, 2002. 
GIMENEZ, T. N.; MATEUS, E. F.; ORTENZI, D. I. B. G.; REIS, S. Crenças de licenciandos em Letras sobre ensino de inglês. Signum: Estudos de Linguagem, Londrina, v. 3, 125-139, 2000.

GIMENEZ, T. N. Learners becoming teachers: an exploratory study of beliefs held by prospective and practising EFL teachers in Brazil. 1994. 346f. Tese (Doutorado em Lingüística e Língua Inglesa Moderna). Lancaster University, Lancaster, 1994.

GUILLAUME, A. M.; RUDNEY, G. L. Student teachers' growth toward independence: an Analysis of their changing concerns. Teaching and Teacher Education, New York, v. 9, n.1, p. 65-80, 1993.

HOLT-REYNOLDS, D. What does the teacher do? Constructivist pedagogies and prospective teachers' beliefs about the role of a teacher. Teaching and Teacher Education, New York, v. 16, n.1, p. 21-32, 2000.

JOHNSON, K. E. The relationship between teachers' beliefs and practices during literacy instruction for non-native speakers of English. Journal of Reading Behavior, Athens, Georgia, v. 14, n. 1, p. 83-108, 1992.

KORTHAGEN, F. A. J. (with KESSELS, J.; KOSTER, B; LAGERWERF, B.; WUBBELS, T.). Linking practice and theory: the pedagogy of realistic teacher education. Mahwah, NJ: Lawrence Erlbaum Associates, 2001. 328p.

KWO, O. Learning to teach English in Hong Kong classrooms: patterns of reflections. In: FREEMAN, D.; RICHARDS, J. C. (Ed.). Teacher learning in language teaching. Cambridge: Cambridge University Press, 1996. p. 295-319. KWO, O.; ADAMSON, B.; TAVARES, N.; TANG, R.; WONG, A. From student teacher to teacher-student: curriculum development for initial teacher education. CONFERENCIA BIANUAL DA ISATT-International Study Association on Teachers and Teaching, 11, Leiden. Anais..., Leiden, 2003.

LUZ, L. T. A. Crenças sobre escrita e seu ensino: implicações para o processo de formação inicial do professor de inglês como língua estrangeira. 2006. $145 f$. Dissertação (Mestrado em Estudos da Linguagem). Universidade Estadual de Londrina, Londrina, 2006.

MANNA, A. L.; MISHEFF, S. What teachers say about their own reading development. Journal of Reading, Newark, v. 31, n. 2, p.160-168, 1987.

MANY, J. E.; HOWARD, F.; HOGE, P. Epistemology and preservice teacher education: how do beliefs about knowledge affect our students' experiences? English Education, v. 34, n. 4, p. 302-322, 2002.

MCNALLY, J.; COPE, P.; INGLIS, B. The student teacher in school: conditions for development. Teaching and Teacher Education, New York, v. 13, n. 5, p. 485498, 1997. 
MILES, M. B.; HUBERMAN, A. M. Qualitative data analysis: an expanded sourcebook. London: Sage Publications, 1994. 338p.

MORINE-DERSHIMER, G. Common learnings from individual experience: the social construction of knowledge by secondary preservice teachers. CONFERÊNCIA BIANUAL DA ISATT-International Study Association on Teachers and Teaching. Anais... Leiden, 2003.

MOSENTHAL, J. H.; SCHWARTZ, R. M.; MACISAAC, D. Comprehension instruction and teacher training: more than mentioning. Journal of Reading, Newark, v. 36, n.3, p. 198-207, 1992.

PACKER, M. J.; WINNE, P. H. The place of cognition in explanations of teaching: a dialog of interpretive and cognitive approaches. Teaching and Teacher Education, New York, v. 11, n. 1. p. 1-21, 1995.

PEACOCK, M. Pre-service ESL teachers' beliefs about second language learning: a longitudinal study. System, v. 29, n. 2, p. 177-195, 2001.

PUPO, J. D. A. M. An investigation into university students' beliefs about reading in English as a foreign language. 1996. 195f. Dissertação (Mestrado em Letras) - Universidade Federal do Paraná, Curitiba, 1996.

PUTNAM, R. T.; BORKO, H. Teacher learning: implications of new views of cognition. In: BIDDLE, B. J.; GOOD, T.L.; GOODSON, I. F. (Ed.). International handbook of teachers and teaching. Dordrecht: Kluwer, 1997. v. II, p. 1223-1296.

RAYMOND, H. C. Learning to teach foreign languages: a case study of six preservice teachers. NECTFL Review, Carlisle, n. 51, p. 16-26, 2002.

REIS, S. Learning to teach reading in English as a foreign language: an interpretive study of student teachers' cognitions and actions. Nijmegen, 2005. 268p.

REIS, S.; GIMENEZ, T.; ORTENZI, D. I. B. G.; MATEUS, E. F. Conhecimentos em contato na formação pré-serviço. In: LEFFA, V. J. (Org.). O professor de linguas estrangeiras: construindo a profissão. Pelotas: Educat, 2001. p. 249-264. RICHARDSON, V. The role of attitudes and beliefs in learning to teach. In: SIKULA, J.; BUTTERY, T. J.; GUYTON, E. (Ed.). Handbook of Research on Teacher Education. New York: Simon Schuster Macmillan, 1996. p. 102-119.

RICHARDSON, V. (Ed.). Constructivist teacher education: building new understandings. London: The Falmer Press, 1997. 191p.

RICHARDSON, V.; PLACIER, P. Teacher Change. In: RICHARDSON, V. (Ed.). Handbook of Research on Teaching. Washington, D.C.: American Educational Research Association, 2001. p. 905-947. 
SILVA, I. M. Percepçôes do que seja ser um bom professor de inglês para formandos de Letras: um estudo de caso. 1998. 115f. Dissertação (Mestrado em Estudos Lingüísticos) - Universidade Federal de Minas Gerais, Belo Horizonte, 1998.

SILVA, K. A. Crenças e aglomerados de crenças de alunos ingressantes em Letras (inglês). 2005. 250f. Dissertação (Mestrado em Lingüística Aplicada) - Instituto de Estudos da Linguagem, Universidade de Campinas, Campinas, 2005.

SILVA, L. O. Crenças sobre aprendizagem de LE de alunos formandos de Letras: um estudo comparativo. 2001. 137f. Dissertação (Mestrado em Estudos Lingüísticos) - Universidade Federal de Minas Gerais, Belo Horizonte, 2001.

SPALDING, E. Of organelles and octagons: what do preservice secondary teachers learn from interdisciplinary teaching? Teaching and Teacher Education, New York, v. 18, n. 6, p. 699-714, 2002.

STOIBER, K. C. The effect of technical and reflective preservice instruction on pedagogical reasoning and problem solving. Journal of Teacher Education, Thousand Oaks, v. 42, n. 2, p. 119-130, 1991.

STRAUSS, A.; CORBIN, J. Basics of qualitative research: grounded theory procedures and techniques. Newbury Park: Sage Publications, 1990. 270p.

TERCANLIOGLU, L. Pre-service teachers as readers and future teachers of EFL reading. TESL-EJ, v. 5, n. 3, 2001. Disponível em: <http://wwwwriting.berkeley.edu/TESL-EJ/ej19/a2.html>. Acesso em: 6 set. 2004.

TILLEMA, H. H. Stability and change in student teacher's beliefs about teaching. Teachers and Teaching: Theory and Practice, London, v. 4, n. 2, p. $217-$ 228, 1998.

WRAY, D. Student teachers' knowledge and beliefs about language. In: BENNETT, N.; CARRÉ, C. (Ed.). Learning to teach. London: Routledge, 1993. p. 51-72.

ZEICHNER, K. Beyond traditional structures of student teaching. Teacher Education Quarterly, San Francisco, v. 29, n. 2, p. 59-64, 2002. 